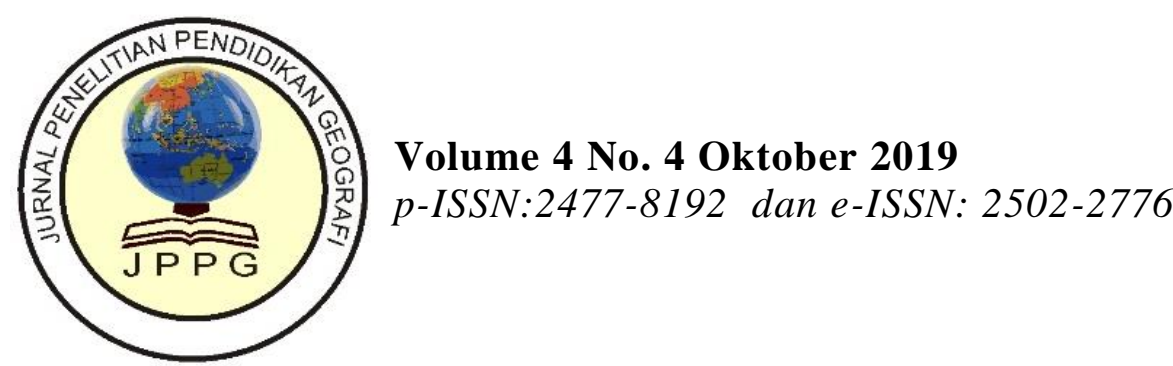

\title{
PENGARUH PENGGUNAAN PUPUK DAN PESTISIDA TERHADAP PRODUKSI PADI SAWAH DI DESA CIALAM JAYA KECAMATAN KONDA KABUPATEN KONAWE SELATAN
}

\author{
Meli Susanti ${ }^{1}$, Ramli $^{2}$, La Ode Amaluddin ${ }^{3}$ \\ ${ }^{1}$ Program Studi Pendidikan Geografi \\ Universitas Halu Oleo \\ Email: melsun235@gmail.com \\ ${ }^{2}$ Program Studi Pendidikan Geografi \\ Universitas Halu Oleo \\ Email: ramlilombe@gmail.com \\ ${ }^{3}$ Program Studi Pendidikan Geografi \\ Universitas Halu Oleo \\ Email: laode.amaluddin@uho.ac.id
}

(Received: 3 September 2019; Accepted: 29 Oktober 2019; Published: 31 Oktober 2019)

(C2019 - Jurnal Penelitian Pendidikan Geografi. Ini adalah artikel dengan

akses terbuka dibawah licenci CC BY-NC-4.0 (http://creativecommons.org/licenses/by-nc/4.0).

\begin{abstract}
Cialam Jaya village has 215 hectares of paddy fields out of a total area of 406.5 hectares in rice planting in Cialam Jaya village, of course using fertilizers and pesticides to support the success of lowland rice production so researchers are interested in examining how partial or simultaneous the effects of fertilizers and pesticides have on production lowland rice in the village of Cialam Jaya. The purpose of the problem in this study are (1) To find out the effect of partial fertilizer use on lowland rice production in Cialam Jaya Village, Konda District, Konawe Selatan Regency. (2) To determine the effect of partial use of pesticides on the production of lowland rice in Cialam Jaya Village, Konda District, Konawe Selatan Regency. (3) To determine the effect of simultaneous use of fertilizers and pesticides on the production of lowland rice in Cialam Jaya Village, Konda District, Konawe Selatan Regency. (4) To find out how much the coefficient is determined the influence of the use of fertilizers and pesticides on the production of lowland rice in Cialam Jaya Village, Konda District, Konawe Selatan Regency. The method used in this study is a quantitative method with multiple linear regression analysis with the Cobb-Douglas production function equation. The results showed that (1) Fertilizers had a significant effect on partially produced paddy rice, (2) Pesticides had a nonsignificant effect on partially produced paddy rice, (3) fertilizers and pesticides had a significant effect on lowland rice production simultaneously with a percentage value of coefficient $56 \%$ terminated and the rest is explained by factors not examined.
\end{abstract}

Keywords: Fertilizers, Pesticides, Lowland Rice, Cialam Jaya, South Konawe.

\section{ABSTRAK}

Desa Cialam Jaya memiliki luas lahan persawahan 215 Ha dari luas keseluruhan 406,5 Ha dalam penanaman padi di desa cialam jaya tentunya menggunakan pupuk dan pestisida sebagai penunjang keberhasilan produksi padi sawah sehingga peneliti tertarik untuk meneliti bagaimana pengaruh pupuk dan pestisida secara parsial dan simultan terhadap produksi padi sawah di desa cialam jaya. Tujuan Masalah dalam penelitian ini adalah (1) Untuk mengetahui pengaruh penggunaan pupuk secara parsial terhadap produksi padi sawah di Desa Cialam Jaya Kecamatan Konda Kabupaten Konawe Selatan. (2) Untuk mengetahui pengaruh penggunaan pestisida secara parsial terhadap 
produksi padi sawah di Desa Cialam Jaya Kecamatan Konda Kabupaten Konawe Selatan. (3) Untuk mengetahui pengaruh penggunaan pupuk dan pestisida secara simultan terhadap produksi padi sawah di Desa Cialam Jaya Kecamatan Konda Kabupaten Konawe Selatan. (4) Untuk mengetahui berapa besar koefisien diterminasi pengaruh penggunaan pupuk dan pestisida terhadap produksi padi sawah di Desa Cialam Jaya Kecamatan Konda Kabupaten Konawe Selatan. Metode yang di gunakan dalam penelitian ini metode kuantitatif dengan analisis regresi linier berganda dengan persamaan fungsi produksi Cobb-Douglas. Hasil penelitian menunjukan bahwa (1) Pupuk memiliki pengaruh yang signifikan terhadap produksi padi sawah secara parsial, (2) Pestisida memiliki pengaruh yang tidak signifikan terhadap produksi padi sawah secara parsial, (3) pupuk dan pestisida memiliki pengaruh yang signifikan terhadap produksi padi sawah secara simultan dengan nilai presentase koefisisen diterminasi $56 \%$ dan sisanya di jelaskan oleh faktor yang tidak diteliti.

Kata Kunci: Pupuk, Pestisida, Padi Sawah, Cialam Jaya, Konawe Selatan.

\section{PENDAHULUAN}

Konawe selatan merupakan penyumbang hasil produksi padi terbesar kedua setelah konawe pada tahun 2015 dengan jumlah produksi yang mencapai 90.867 ton (Badan Pusat Statistik Sultra, 2015). Dan salah satunya adalah desa cialam jaya kecamatan konda kabupaten konawe selatan dengan luas lahan garapan sawah seluas 215 ha, jenis padi yang di produksi desa cialam jaya adalah jenis tanaman padi sawah.

Padi sebagai tanaman utama sangat disukai daripada tanaman lain seperti terigu dan jagung. Ini di buktikan dengan Kebutuhan pangan masyarakat di Indonesia sebesar 96,09\% Pada Tahun 2015 Data Badan Pusat Statistik mencatat lahan pertanian yang ada di seluruh Indonesia mencapai 8.807.393 ha.

Pertumbuhan pangan di Indonesia dalam hal pertanian contohnya padi, di butuhkan sebuah inovasi yang dapat menjaga kualitas tanaman tersebut. salah satu inovasi tersebut yaitu dengan adanya pemupukkan dan penggunaan Pestisida yang berimbang.

Pemupukkan merupakan salah satu usaha untuk menambahkan ketersediaan unsur hara yang di perlukan oleh tanaman, lain dari itu pemupukkan di perlukan untuk memperbaiki sifat fisik, biologi dan kimia tanah. Sedangkan Pestisida adalah bahan yang digunakan untuk mengendalikan, menolak, memikat, atau membasmi organisme pengganggu (Hamidah, 2010).

Pendayagunaan sumber daya pertanian ini menjadi kunci dalam meningkatkan produkvitas pertanian, sehingga sumber daya yang terbatas itu harus dialokasikan seefisien mungkin. Seperti di ketahui sumber daya pertanian yang terdiri dari lahan, tenaga kerja, air, termasuk unsur-unsur yang terkandung didalamnya merupakan sumber daya yang utama untuk kelangsungan hidup manusia. Pengelolaan yang tidak bijaksana dan mengacu kedepan akan berakibat menurunya kulitas sumber daya itu sendiri yang akhirnya berpengaruh terhadap produkvitas pertanian (Hardiana dan Surdin, 2019).

Masyarakat Desa Cialam Jaya dikenal sebagai komunitas yang dalam kehidupan seharihari sebagian besar menggantungkan hidupnya pada pertanian, di Desa Cialam Jaya, produksi padi sawah dari tahun ke tahun terjadi peningkatan dan penurunan yang disebabkan oleh berbagai faktor.

\section{METODE PENELITIAN Lokasi Penelitian}

Penelitian ini dilaksanakan di wilayah Kabupaten Konawe Selatan, Kecamatan Konda, Desa Cialam Jaya. Dengan pertimbangan konawe selatan merupakan penghasil padi terbesar kedua setelah konawe di Sulawesi Tenggara.

\section{Populasi Dan Sampel}

Populasi dalam penelitian ini sebanyak 300 orang. sampel dalam penelitian ini sebanyak 30. Apabila jumlah populasinya besar, maka dapat diambil $10-15 \%$ atau $20-30 \%$ tergantung dari kemampuan peneliti (Riwidikdo, 2013).

\section{Identifikasi Variabel Penelitian}

Dalam penelitian ini menggunakan dua jenis variabel yaitu variabel (Independent) Pupuk dan Pestisida (dependent) Produksi.

\section{Jenis Dan Sumber Data}

Sumber data yang digunakan dalam penelitian ini adalah, sumber data primer terdiri dari penyebaran kuesioner berupa angket untuk 
mengetahui adanya pengaruh penggunaan pupuk dan pestisida terhadap produksi padi sawah, melakukan wawancara terbuka dengan menggunakan pedoman wawancara untuk penegasan pernyataan mengenai penggunaan pupuk dan pestisida, dokumentasi pengambilan data berupa gambar dengan alat kamera. Yang kedua Data sekunder data yang diperoleh dari kantor dan instansi yaitu kantor desa Cialam Jaya.

Teknik Pengumpulan Data

Teknik pengumpulan data dalam penelitian ini adalah Observasi peninjauan lapangan penelitian secara langsung, pembagian kuesioner berupa angket, melakukan wawancara terbuka, dan pengambilan gambar sebagai dokumentasi.

\section{Teknik Analisis Data}

Tahapan teknik analisis data pada penelitian ini yaitu analisis data kuantitatif dengan menggunakan dua pendekatan yang pertama kuantitatif deskriptif menghitung total, range, modus, median dan lain-lainnya. Kedua kuantitatif inferensial kalkulasi data melalui pengujian Analisis Linier Berganda, uji asumsi klasik, ujit t, uji f dan koefisien diterminasi.

HASIL DAN PEMBAHASAN

Uji Asumsi Klasik

Tabel 1. Uji Normalitas

\begin{tabular}{llr}
\hline $\mathbf{N}$ & & Unstandardized Residual \\
\hline Normal Parameters & & $\mathbf{3 0}$ \\
& Mean & .0000000 \\
Most Extreme Differences & Std. Deviation & 2.04579481 \\
& Absolute & .169 \\
& Positive & .169 \\
Kolmogorov-Smirnov Z & Negative & -.124 \\
Asymp. Sig. (2-tailed) & & .927 \\
a. Test distribution is Normal. & & .357 \\
b. Calculated from data. & & \\
\hline
\end{tabular}

Sumber: Hasil Analisis Data Primer, 2018.

Berdasarkan hasil pengujian pada tabel $1 .>0,005(0,357>0,05)$. Berdasarkan hasil Hasil pengujian One Sample Kolmogorov- tersebut, maka dapat di simpulkan bahwa model Smirnov Test mengasilkan asymtotic significance regresi telah memenuhi asumsi kenormalan.

Tabel 2. Uji Multikolineritas

\begin{tabular}{ccc}
\hline \multirow{2}{*}{ Model } & \multicolumn{2}{c}{ Collinearity Stastistics } \\
\cline { 2 - 3 } & \multicolumn{2}{c}{ Tolerance } \\
(contestant) & .907 & 1.103 \\
Pupuk & .907 & 1.103 \\
Pestisida & & \\
\hline Dependent Variable: Y (Produksi) & & \\
\hline
\end{tabular}

Sumber: Hasil Analisis Data Primer, 2018

Hasil nilai Variance Inflation Factor (VIF) dengan menggunakan SPSS 21 pada tabel diatas, dapat disimpulkan bahwa antar variabel bebas nilai VIF $<10$ dan nilai Tolerance $>0,10$ maka

tidak terjadi Multikolineritas.

\section{Uji Regresi Linier Berganda}

Tabel 3. Uji t atau Uji Parsial 


\begin{tabular}{|c|c|c|c|c|c|c|}
\hline \multirow{2}{*}{\multicolumn{2}{|c|}{ Model }} & \multicolumn{2}{|c|}{$\begin{array}{l}\text { Unstandardized } \\
\text { Coefficients }\end{array}$} & \multirow{2}{*}{$\begin{array}{c}\text { Standardized } \\
\text { Coefficients } \\
\text { Beta } \\
\end{array}$} & \multirow[t]{2}{*}{$\mathrm{t}$} & \multirow[t]{2}{*}{ Sig. } \\
\hline & & B & Std. Error & & & \\
\hline \multirow[t]{3}{*}{1} & (Constant) & -15.207 & 8.148 & & -1.866 & .073 \\
\hline & pupuk (x1) & 1.030 & .180 & .728 & 5.720 & .000 \\
\hline & pestisida (x2) & .250 & .263 & .121 & .953 & .349 \\
\hline & ependent Varial & roduksi & & & & \\
\hline
\end{tabular}

Sumber: Hasil Analisis Data Primer, 2018

a. Pengujian Hipotesis Pertama (H1)

Diketahui nilai Signifikansi untuk pengaruh pupuk terhadap produksi adalah sebesar $0,000>0,05$ dan nilai t hitung 5,720 > 2,052 sehinggah dapat disimpulkan bahwa H1 Diterima yang berarti terdapat pengaruh variabel pupuk $\left(\mathrm{X}_{1}\right)$ terhadap produksi $(\mathrm{Y})$. b. Pengujian Hipotesis Kedua (H2)

Diketahui nilai Signifikansi untuk pengaruh pestisida terhadap produksi adalah sebesar 0,349>0,05 dan nilai t hitung 0,953 < 2,052 sehinggah dapat di simpulkan bahwa $\mathrm{H} 2$ ditolak yang berarti tidak ada pengaruh pestisida $\left(\mathrm{X}_{2}\right)$ terhadap produksi ( $\mathrm{Y}$ ).

Tabel 4. Uji F atau Uji Simultan

\begin{tabular}{ccccccc}
\hline \multicolumn{7}{c}{ ANOVA $^{\mathbf{a}}$} \\
\hline \multirow{3}{*}{1} & Model & Sum of Squares & df & Mean Square & F & Sig. \\
& Regression & 143.895 & 2 & 71.947 & 19.431 & $.000^{\mathrm{b}}$ \\
& Residual & 99.972 & 27 & 3.703 & & \\
& Total & 243.867 & 29 & & & \\
\hline
\end{tabular}

a. Dependent Variable: produksi (y)

b. Predictors: (Constant), pestisida (x2), pupuk (x1)

Sumber: Hasil Analisis Data Primer, 2018.

c. Pengujian hipotesis ketiga (H3)

Berdasarkan tabel diketahui nilai signifikansi untuk pengaruh pupuk dan pestisida secara simultan terhadap produksi adalah sebesar sehinggah dapat disimpulkan bahwa H3 diterima yang berarti terdapat pengaruh pupuk dan pestisida secara simultan terhadap produksi. $0,000<0,05$ dan nilai $\mathrm{F}$ hitung 19,431 > 3,32,

Tabel 3. Koefisien Diterminasi

\begin{tabular}{lccrr}
\hline \multicolumn{5}{c}{ Model Summary } \\
\hline Model & $\mathrm{R}$ & $\mathrm{R}$ Square & Adjusted R Square & Std. Error of the Estimate \\
1 & $.768^{\mathrm{a}}$ & .590 & .560 & 1.92423 \\
a. Predictors: (Constant), pestisida (x2), pupuk (x1) & & \\
\hline
\end{tabular}

Sumber: Hasil Analisis Data Primer, 2018

Koefisien diterminasi $\left(\mathrm{R}^{2}\right)$ adalah sebesar 0,56. Hal ini dapat diartikan bahwa pembuktian $\mathrm{H} 4$ variabel independent (pupuk dan pestisida) memiliki pengaruh terhadap variabel

\section{PEMBAHASAN}

Desa cialam jaya merupakan salah satu desa yang berada di kecamatan Konda kabupaten dependent (Produksi) secara simultan sebesar $56 \%$, sedangkan sisanya diterangkan oleh faktor lain yang tidak diteliti.

Konawe Selatan memiliki luas daerah 406,5 Ha dengan luas lahan garapan sawah seluas $215 \mathrm{Ha}$. Masyarakat cialam jaya mayoritas melakukan kegiatan bertani dan menggantungkan hidup mereka pada sektor tani padi sawah. 
Apabila di lihat kembali, masyarakat desa cialam jaya secara keseluruhan hampir melakukan kegiatan bertani padi sawah. Dalam proses bertani tersebut tentunya mereka pasti memiliki unsur-unsur yang dapat membuat hasil panen mereka melimpah. Dua di antara berbagai unsur tersebut yaitu penggunaan pupuk dan pestisida.

Menurut (Hamidah, 2010) pupuk merupakan bahan alami maupun buatan yang ditambahkan kedalam tanah, agar dapat meningkatkan unsur hara dan kesuburan tanah. dan pestisida merupakan zat atau campuran yang digunakan untuk mencegah, memusnahkan, menolak, atau memusuhi hama dalam bentuk hewan, tanaman dan mikro-organisme pengganggu (Zulkarnain, 2010).

Dalam penggunaan pupuk dan pestisida tentunya memiliki aturan dan takaran yang dianjurkan, pupuk yaitu Urea 100 Sampai 150 $\mathrm{kg} / \mathrm{Ha}$ dan NPK $300 \mathrm{Kg} / \mathrm{Ha}$, Pestisida DMA 1 liter perhektar, Spontan 0,75 sampai 1,5 liter perhektar dan Stuntmant 0,75 sampai 1,5 per Hektar menurut (Balai Pengkajian Teknologi Pertanian, 2011).

Produksi padi sawah petani responden Desa Cialam Jaya setelah diolah, hasil produksi padi sawah petani responden desa cialam jaya sebanyak 3,597 $\mathrm{kg}$ atau jika di setarakan pada satuan ton akan mendapatkan 3,59 Ton dengan luas lahan rata-rata seluas $1,15 \mathrm{Ha}$, penggunaan pupuk rata-rata sebanyak $337 \mathrm{Kg}$, dan penggunaan pestisida sebanyak rata-rata 1,8 liter dalam 1 kali periode penanaman padi sawah atau selama masa 3 kali panen.

Apabila di bandingkan pada tahun 2017 lalu produksi padi sawah desa cialam jaya mengalami peningkatan sebesar $3,804 \mathrm{Kg}$ atau setara 3,80 ton dalam 3 kali panen hal ini menggambarkan bahwa pada tahun 2018 produksi padi sawah petani responden mengalami penurunan sebanyak $207 \mathrm{~kg}$.

Penurunan produksi padi sawah petani responden diakibatkan dari beberapa faktor seperti penggunaan pestisida yang tidak sesuai dengan takaran yang telah di atur oleh BPTP (Balai Pengkajian Teknologi Pertanian) yaitu DMA 1 liter perhektar, Spontan 0,75 sampai 1,5 liter perhektar dan Stuntmant 0,75 sampai 1,5 per Hektar. karena biaya harga pestisida yang mahal ditambah lagi hama atau penyakit semakin mewabah.

\section{KESIMPULAN}

Berdasarkan hasil yang diperoleh dari penelitian ini maka dapat disimpulksn sebagai berikut: 1) Pupuk memiiliki pengaruh yang positif dan signifikan terhadap produksi padi sawah; 2) Pestisida tidak memiiliki pengaruh yang positif dan signifikan terhadap produksi padi sawah; 3) Pupuk dan pestisida memiiliki pengaruh positif dan signifikan secara simultan terhadap produksi padi sawah; 4) Nilai dari koefisien diterminasi presentase $56 \%$, sedangkan sisanya diterangkan oleh faktor lain yang tidak diteliti.

\section{SARAN}

Berdasarkan hasil penelitian ini terdapat beberapa saran yang berguna untuk peneliti selanjutnya: 1) Kepada petani padi sawah agar lebih memperhatikan dengan baik penggunaan pupuk dan pestisida, penggunaan yang sesuai peraturan dan anjurannya guna untuk meningkatkan hasil produksi padi sawah yang memadai; 2) Untuk meningkatkan hasil produksi padi sawah petani juga perlu untuk memperhatikan jenis pupuk dan pestisida yang cocok untuk digunakan agar tidak menimbulkan efek samping pada tumbuhan padi sawah maupun pada kesehatan petani produsennya; 3) Perlu adanya pembinaan dalam bentuk penyuluhan dari instansi yang terkait secara lebih intensif lagi tentang mengenai tata cara pengelolaan produksi padi sawah yang lebih baik, khususnya dalam hal penggunaan sarana produksi.

\section{UCAPAN TERIMA KASIH}

Terima kasih kepada kedua orang tua, Bapak Drs. Ramli, M.Si., selaku pembimbing I dan Bapak, La Ode Amaluddin, S.Pd., M.Pd., selaku pembimbing II serta para reviewer dan editor Jurnal Penelitian Pendidikan Geografi.

\section{DAFTAR PUSTAKA}

Badan Pusat Statistik. (2015). Hasil Sensus Penduduk 2015, Data Agregat Per Provinsi. Jakarta: BPS. https://www.bps.go.id (Diakses, Agustus 2018).

Balai Pengkajian Teknologi Pertanian (BPTP), (2011). Jerami Padi Sebagai Bahan Organik di Lahan Sawah. Leaflet, Jawa Barat. http://bbpadi.litbang.pertanian.go.id/index.p hp/info-berita/info-teknologi/jerami-sebagaibahan-organik (Diakses, Agustus 2018). 
Hamidah. (2010). Pengertian, Manfaat, Jenis, Dan Pemilihan Pupuk http://www.ipteknet.com (Diakses, Agustus 2018)

Hardiana, dan Surdin. (2019). Analisis Pendapatan Petani Kacang Tanah di Desa Lalemba Kecamatan Lawa Kabupaten Muna Barat. Jurnal Penelitian Pendidikan Geografi Volume 4 No. 3 Juli 2019: 98-106.

Sugiyono. (2013). Metode Penelitian Kuatitatif, Kualitatif dan $R \& D$. Bandung: Alfabeta.

Sugiyono. (2017). Metode Penelitian Kombinasi (Mixed Methods). Bandung: Alfabeta.

Riwidikdo, H. (2013). Statistik Kesehatan dan Aplikasi SPSS dalam Prosedur Penelitian. Yogyakarta: Rohima Press.

Zulkarnain, I., 2010. Aplikasi Pestisida dan Analisa Residu Pestisida. Universitas Sumatera Utara, Medan. http://repository.usu.ac.id/bitstream/handle/1 23456789/16894/Cover.pdf?sequence $=7 \&$ is Allowed=y (Diakses, Agustus 2018). 